\title{
Computation of Beam Stress and RF Performance of a Thin Film Based Q-Band Optimized RF MEMS Switch
}

\author{
Tejinder Singh ${ }^{\dagger}$ \\ Discipline of Electronics and Electrical Engineering, Lovely Professional University, Phagwara 144 402, PB, India
}

Received March 22, 2015; Revised May 19, 2015; Accepted June 28, 2015

\begin{abstract}
In lieu of the excellent radio frequency (RF) performance of microelectromechanical system ( MEMS) switches, these micro switches need higher actuation voltage for their operation. This requirement is secondary to concerns over the swtiches' reliability. This paper reports high reliability operation of RF MEMS switches with low voltage requirements. The proposed switch is optimised to perform in the Q-band, which results in actuation voltage of just $16.4 \mathrm{~V}$. The mechanical stress gradient in the thin micro membrane is computed by simulating von Mises stress in a multi-physics environment that results in $90.4 \mathrm{MPa}$ stress. The computed spring constant for the membrane is $3.02 \mathrm{~N} / \mathrm{m}$. The switch results in excellent RF performance with simulated isolation of above $38 \mathrm{~dB}$, insertion loss of less than $0.35 \mathrm{~dB}$ and return loss of above $30 \mathrm{~dB}$ in the Q-band.
\end{abstract}

Keywords: High-isolation, Capacitive switch, RF MEMS, Meanders, Low-voltage

\section{INTRODUCTION}

Over recent years, microelectromechanical system (MEMS) based devices especially radio frequency (RF) switches have attracted much attention from both academics and industrial experts. RF-MEMS switches replaced the conventional semiconductor based devices like gallium arsenide field-effect transistors (GaAs FETs), metal-semiconductor-field-effect transistors (MESFETs) and p-i-n diode switches. RF MEMS has many advantages, including high isolation, low insertion loss, excellent linearity and negligible power consumption [1].

Usually, MEMS switches are fabricated using surface micromachining processes and have a suspended thin metal membrane (fixed-fixed or cantilever), which activates or deactivates the RF signal transmission through mechanical movement of the beam above the signal line of the co-planar waveguides $[2,3]$.

${ }^{\dagger}$ Author to whom all correspondence should be addressed: E-mail: tejinder.singh@ieee.org

Copyright $@ 2015$ KIEEME. All rights reserved. This is an open-access article distributed under the terms of the Creative Commons Attribution Non-Commercial
License (http:///creativecommmons.org/licenses/by-nc/3.0) which permits unrestricted noncommercial use,
distribution, and reproduction in any medium, provided the original work is properly cited. distribution, and reproduction in any medium, provided the wiginal permits unrestricted is no
Deposition-based processes have some limitations that can complicate the process of fabrication and, thus, affect performance inherently [4]. Limited layer thickness limits the restoring force and stiffness in MEMS structures. Moreover, there is also a need for switches that can be used for low voltage application. Such requirements limit the use of conventional MEMS designs [5].

Researchers have proposed various designs that solve the MEMS issues [6]. Various types for RF MEMS switches address issues like low voltage and reliability concerns, because the primary engineering concepts only deal with the design of the beam. We have presented the design of a capacitive shunt type RF MEMS switch that not only addresses these concerns but also requires very low operation voltage because it is compact $[7,8]$.

This paper presents a compact and capacitive/shunt RF MEMS switch for Q-band operation [9]. Being a compact switch, this switch shows prominent performance in the higher frequency region. Increasing the electrodes area can compensate for the issue of high actuation voltage but then it also limits the compact switch design. Thus, in this paper the switch membrane is designed with a small footprint. The inclusion of meanders on all sides helps to lower the effective spring constant and 
stress in the membrane and further provides a good mechanical restoring force. The proposed switch design shows excellent performance in the Q-band frequencies and performance for various other bands is also given in a tabular form. Stress and voltage requirements are computed using a finite element modeller (FEM) [10].

\section{THEORY}

The theory section provides the analytically modeling of various aspects of the switch. However in [5], various aspects have been covered in detail, but the theory is provided as a reference for readers regarding the issues in RF MEMS. These formulas are also used to model switches in the FEM for the computation of various solutions to the problem.

Basically, the electrostatic fields that can be modelled locally in a one-dimensional capacitor model can be analysed. The capacitance is given by the following equation that defines the integral over the overlap area between the membrane and signal line. However, the error introduced by this one-dimensional model is usually less than $5 \%$.

$$
C=\int \frac{\varepsilon_{0} w W t}{g_{0}(x)+k_{d} / \varepsilon_{\mathrm{r}}}
$$

where, $\varepsilon_{0}$ is the permittivity of air, $w$ is the length of the overlapping area and $\mathrm{W}$ is the width of the overlapping area, while, $t$ is the thickness of the membrane. $g_{0}(x)$ is the gap between the membrane and the dielectric layer over the signal line, $k_{d}$ is the depth of the dielectric layer and $\varepsilon_{\mathrm{r}}$ is the dielectric constant.

Electrostatic forces on the membrane in the overlap area at the actuation voltage $V_{p}$ are described by the pressure $P$, which can be given by and defined as an FEM expression. $\mathrm{P}$ is used as a load in the solution of a given problem in FEM.

$$
P(x)=-\frac{\varepsilon_{0} V_{p}^{2}}{2\left(g_{0}(x)+k_{d} / \varepsilon_{r}\right)^{2}}
$$

The integrand of Eq. (1) can also be defined as an FEM expression that can further be numerically integrated to obtain capacitance.

The damping or squeeze film damping that can further dominate the performance of the RF MEMS switch is driven by the vertical motion of the membrane and is caused by the viscosity and inertia of the gas that is squeezed in or out of the in between gap of the membrane and dielectric layer on the signal line. It is described by the Reynolds equations as:

$$
\nabla \cdot\left(\frac{\rho g_{0}^{3}}{\mu_{e f f}} \nabla P\right)=12 \frac{\partial\left(\rho g_{0}\right)}{\partial t}
$$

where $P$ is the pressure of gas, $g_{0}$ is the air gap, $\mu_{\text {eff }}$ is the density of the gap and $\mu_{\text {eff }}$ is the effective viscosity that takes into account the small scale of the air gap that is $3 \mu \mathrm{m}$ in this case and is approximated analytically by:

$$
\mu_{e f f}=\frac{\mu}{1+9.64\left(\lambda / g_{0}\right)^{1.16}}
$$

where, $\lambda$ is the mean free path of the gas in the air gap at ATP. The mean free path $\lambda$ is approxmately $70 \mathrm{~nm}$. At very slow transients, the time derivative in Eq. (3) is dominated by the variation in the air gap, $g_{0}$ while the variation in the density of gas plays a crucial role at high frequencies. This is investigated in [5] for the parallel-plate system assuming a variation of a small air gap. The following corner frequencies are derived by:

$$
f_{c}=\frac{P_{0} g_{0}^{2}}{24 \pi \mu_{e f f} w^{2}}
$$

where $\mathrm{P}_{0}$ is the surrounding pressure, $\mathrm{w}$ is the width of the overlapping area, and the gas is assumed to be isothermal. Below this frequency, Eq. (3) can be simplified by eliminating the density constant Q.

\section{STRUCTURE AND PRINCIPLE OF OPERATION}

The proposed RF MEMS switch is designed on a $200 \mu \mathrm{m}$ thick substrate of quartz material which serves as the base of the RF MEMS switch. Co-planar waveguides (CPW) are used for RF signal transmission from the input port to the output port. A high$\mathrm{k}$ dielectric layer of hafnium dioxide $\left(\mathrm{HfO}_{2}\right)$ is applied over the substrate. The operation principle of the proposed switch is the same as the typical shunt type fixed-fixed beam RF MEMS switch and is shown in Fig. 1. The CPW is characterized at $Z_{0}=50: \Omega$ for ease in coupling with coaxial cables.
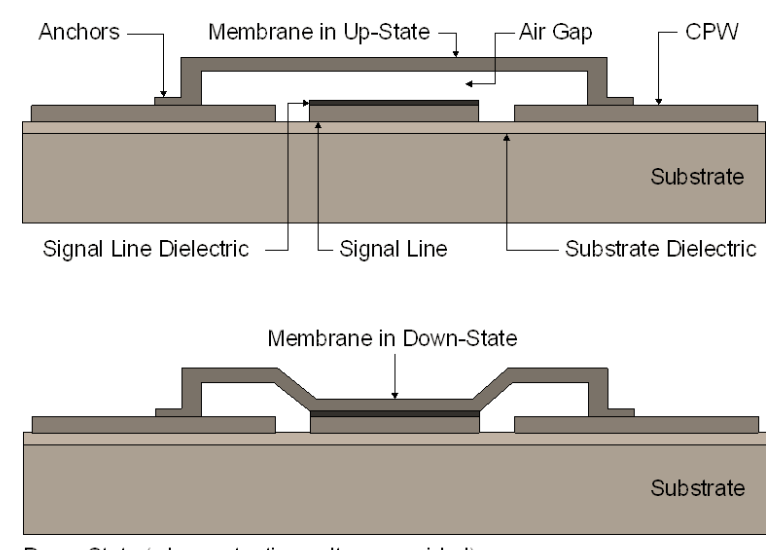

Down-State (when actuation voltage provided)

Fig. 1. Operational principle of capacitive/shunt RF MEMS switch in ON and OFF state implemented on a substrate and CPW lines.

As the membrane has a compact design, the central signal line is optimized with a G/S/G of 40/75/40. The beam is suspended using crab type meanders connected to four anchors. To lower the pull-down voltage, two $40 \mu \mathrm{m}$ wide electrodes are used for electrostatic actuation. A gap height of $3 \mu \mathrm{m}$ is maintained between the central part of the membrane and the RF signal line. The gap height is optimized and selected using pull-in voltage 
analysis in a finite element modeller. If the gap height was lower than this value, the membrane would be prone to self-biasing and this can reduce reliability due to issues like stiction of the thin beam. In that case, the mechanical restoring force becomes weaker to pull the membrane in its rest position [11] as shown in Fig. 4. The switch geometry is shown in Fig. 2.

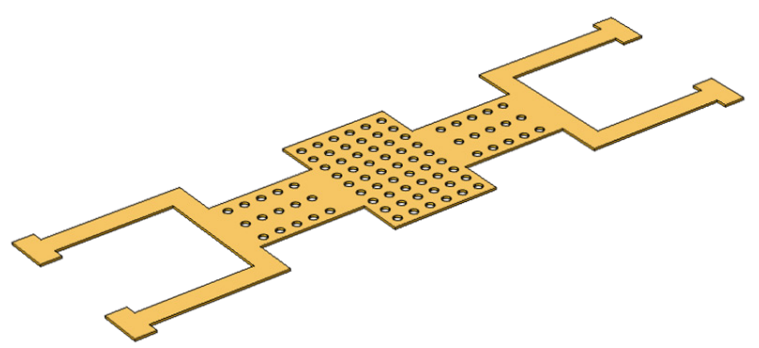

Fig. 2. Geometry of proposed compact RF MEMS switch.

\subsection{Membrane design}

Gold $(\mathrm{Au})$ is used as a relevant material for the beam design [12]. The contact area of the membrane has holes to decrease air damping [5]. Biaxial residual stress is not present in a micromachined membrane that has holes [6]. The contact area of the membrane is connected with two parts that come in to contact with the electrodes. $10 \mu \mathrm{m}$ wide meanders are designed for this membrane. These meanders are attached as a U-shape geometry on both sides. These meanders for such a compact area of membrane help to restore the membrane to its rest position in an OFF state of the switch with a trade-off in spring constant that is a little higher [13]. The complete structure is suspended over the CPW lines. Four meanders are amalgamated on the top end. The close-up view of the membrane is shown in Fig. 2.

The proposed switch is designed in a generic CAD environment and the dimensions and materials used to design the switch are given in Table 1. The area of the complete switch is $0.7 \mathrm{~mm} \backslash \mathrm{s} \backslash \mathrm{up} 5(2)$. The specifications of membrane are given in Fig. 3.

Table 1. Switch specifications.

\begin{tabular}{ccccc}
\hline Component & $\begin{array}{c}\text { Length } \\
\mu \mathrm{m}\end{array}$ & $\begin{array}{c}\text { Width } \\
\mu \mathrm{m}\end{array}$ & $\begin{array}{c}\text { Depth } \\
\mu \mathrm{m}\end{array}$ & $\begin{array}{c}\text { Material } \\
\text { Used }\end{array}$ \\
\hline \hline Substrate & 700 & 150 & 200 & Quartz Glass \\
\hline $\begin{array}{c}\text { Substrate } \\
\text { Dielectric }\end{array}$ & 700 & 150 & 0.5 & $\mathrm{HfO}_{2}$ \\
\hline CPW (G S G) & 40 & 75 & 40 & Gold \\
\hline $\begin{array}{c}\text { Membrane's } \\
\text { Meanders }\end{array}$ & 60 & 80 & 10 & Gold \\
\hline $\begin{array}{c}\text { Meanders } \\
\text { Thickness }\end{array}$ & - & 3 & 1 & Gold \\
\hline Contact Area & 40 & 35 & 1 & Gold \\
\hline Holes Area & 3.8 & 3.8 & 1 & N.A. \\
\hline
\end{tabular}

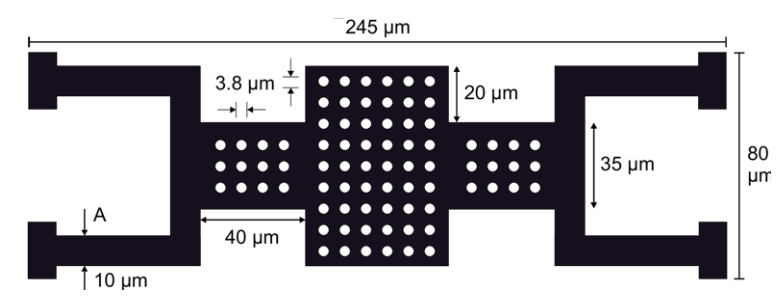

Fig. 3. Dimensions of membrane and meanders showing specifications of holes and contact area.

\section{SWITCH CHARACTERISTICS}

The forces act on the contact area of the membrane. As a result, the load is distributed on one-third of the area in the centre of the membrane if the load is distributed on the central component. As discussed, there is no residual stress. The force distribution on the membrane is shown in Fig. 4. Hence, the spring constant component purely depends on the force applied [14,15].

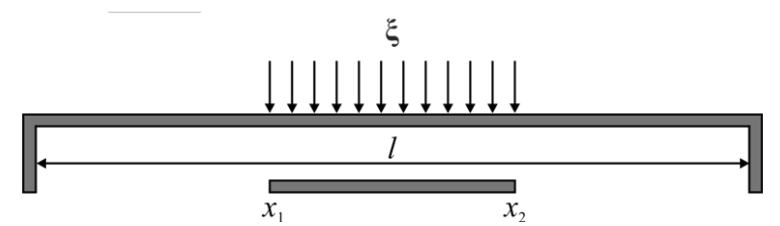

Fig. 4. Force distribution on the switch membrane. $\xi$ is the force applied in a vertical Z-direction and the electrostatic actuation is applied from $\mathrm{x}_{1}$ to $\mathrm{x}_{2}$.

In this case, the force is distributed on both sides of the central contact, but due to that force, the central component is forced to come down in a $\mathrm{Z}$ direction to make complete contact with the signal line.

The force distribution can be estimated using [11]:

$$
y=\frac{2}{E I} \int_{x_{1}}^{x_{2}} \frac{\xi}{48}\left(l^{3}-6 l^{2} a+9 l a^{2}-4 a^{3}\right) d a
$$

where; $\xi$ is the load per unit of length 1 , I is moment of inertia and $E$ is Young's modulus of material. Integrating the equation (6) from $\mathrm{x}_{1}$ to $\mathrm{x}_{2}$ will give an approximation of the force distribution.

The load per unit length can be computed using:

$$
P=\xi 2\left(x_{1}-x_{2}\right)
$$

The spring constant of the Au metal membrane is analyzed using FEM [3]. The analyzed spring constant for the membrane is $3.02 \mathrm{~N} / \mathrm{m}$. Thus, using the analyzed spring constant $\mathrm{k}$, the pullin voltage can be computed and simulated. The voltage of the switch can be computed using:

$$
V_{p}=\sqrt{\frac{8 k}{27 \in_{0} w W} g_{0}^{3}}
$$

where; $\varepsilon_{0}$ is the permittivity of free space, is the gap between the membrane and the electrode; $\mathrm{wW}$ is the area of the electrode used for actuation, $w$ is length and $\mathrm{W}$ is the width of the electrode. The analytical value of the actuation voltage required for $\mathrm{g}_{0}=3$ is 16.4 . Although the pull-in voltage is analyzed and compared with numerical calculations, the pull-out occurs due to the elastic recovery forces of the meanders. Hence, even for the low-k membrane, recovery forces are higher and switch stiction chances are very low. 


\section{EQUIVALENT CIRCUIT MODELING}

The equivalent circuit model of the proposed RF MEMS switch is shown in Fig. 5. The electromagnetic model for these switches can be estimated with a corresponding C-L-R circuit model. The transmission lines are terminated by characteristic impedance $\mathrm{Z}_{0} .1$ is the infinite length reliant on the transmission line gap and the ohmic switch area, $\mathrm{C}_{\mathrm{s}}$ is the series capacitance between the ohmic contact and transmission line, and $\mathrm{R}_{\mathrm{c}}$ is the contact resistance. Two equal ohmic contact resistances $\mathrm{R}_{\mathrm{c}}$ and capacitance $\mathrm{C}_{\mathrm{s}}$ are considered. The parasitic capacitance between the open ends of the signal line is denoted by $\mathrm{C}_{\mathrm{p}}$. With the alteration in geometry of the switch, the parameters like R, L ,C or parasitic capacitance can be modified according to the performance requirements.

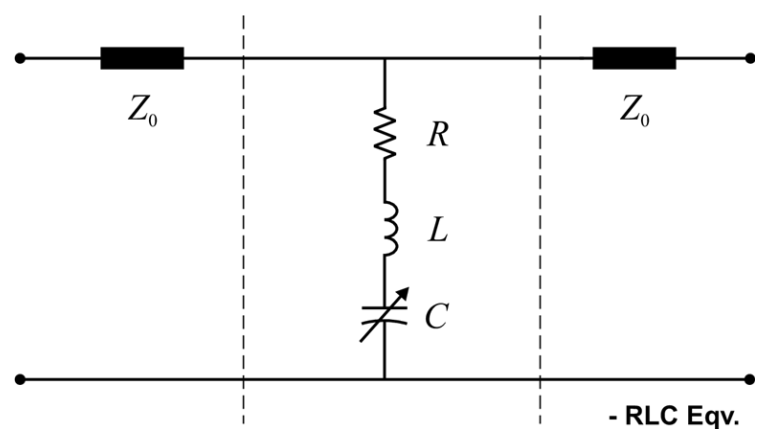

Fig. 5. Equivalent circuit model of RF MEMS DC contact switch.

The C-L-R parametric analysis is performed for the model shown in Fig. 5. This results in capacitance of $1.38 \mathrm{fF}$ and series resistance of $0.82 \Omega$. The dimensions of CPW are specified in Table 1. If $\mathrm{C}$ is the capacitance per unit length of line 1 and $\mathrm{C}_{0}$ is the capacitance per unit length in the absence of the dielectric layer, then the effective permittivity $\mu_{\text {eff }}$ for CPW is approximated by using:

$$
\epsilon_{e f f}=\frac{C}{C_{0}}=1+\frac{1}{2}\left(\epsilon_{r}-1\right)\left(\frac{K(k)}{K\left(k^{\prime}\right)} \times \frac{K\left(k_{s}^{\prime}\right)}{K\left(k_{s}\right)}\right)
$$

where; $\mathrm{K}$ is the complete elliptical integral of the first kind, and the values of $k$ and $k^{\prime}$ depend on the geometry configuration of the line and are demonstrated in [11].

The capacitance can be numerically computed using:

$$
C_{s}=\frac{C_{C}}{2}+C_{g}
$$

where $\mathrm{C}_{\mathrm{g}}$ is the signal-line coupling capacitance in the OFF state due to the gap in the signal line. $\mathrm{C}_{\mathrm{c}}$ is the contact capacitance of the switch. The series resistance (in $\Omega$ ) and inductance (in $\mathrm{pH}$ ) for the switch is calculated as $0.82 \Omega$ and $104 \mathrm{pH}$, respectively.

The LC resonant frequency $\mathrm{f}_{0}$ of the switch can be computed using:

$$
f_{0}=\frac{1}{2 \pi \sqrt{L C}}
$$

where $\mathrm{L}$ and $\mathrm{C}$ are the value of inductance and capacitance.

\section{STRESS ANALYSIS USING FEM}

To compute the effective stress in the membrane, we have modeled the structure in the finite element modeler. Before computing the model in the FEM, meshing is required as it plays a crucial part in reducing the time of computation. The meshing of the membrane in the FEM can be seen in Fig. 6. Smaller mesh gives a more realistic solution. The effect of von Mises stress in the membrane for the required force at the specific spring constant is analyzed.

Figure 7 demonstrates that the gold membrane shows an approximate stress of $90 \mathrm{MPa}$, which is good enough for gold and less than the ultimate tensile strength of the material. That simply points to the robustness and reliability of meanders in the membrane, as this membrane can withstand many more switching cycles then the membrane made using aluminium $[3,15]$. This provides more room for the stress gradient. In short it can handle more stress.

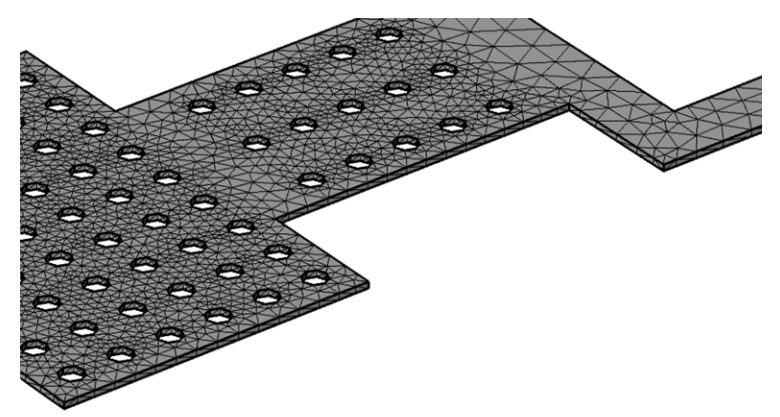

Fig. 6. Close-up view of maximum stress prone areas in the gold membrane.

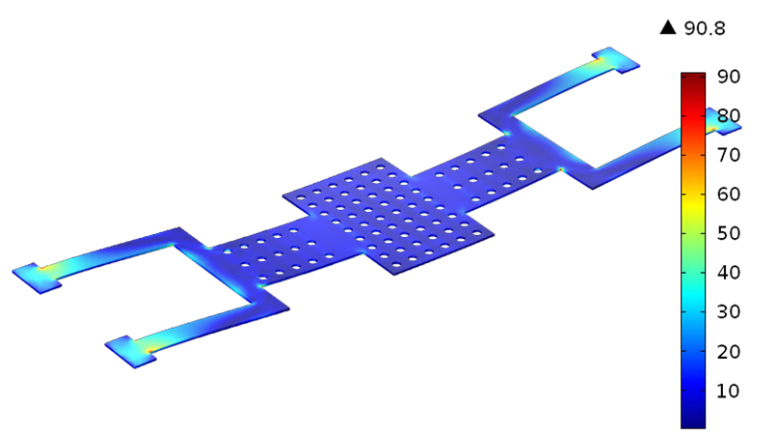

Fig. 7. Stress analysis demonstrating maximum stress of $90 \mu \mathrm{m}$.

The deflection can be seen in Fig. 8 and Fig. 9 respectively. From Fig. 9, it is clear that the contact is made properly with the signal line. The spring constant is computed by applying load on the contact area of the membrane. Furthermore, the actuation voltage requirements are given in Table 2. The spring constant plot is shown in Fig. 11 and voltage requirement vs. deflection is shown in Fig. 12. The switch needs $16.4 \mathrm{~V}$ for the displacement of $\mathrm{g}_{0}$ as the displacement can be seen in Fig. 10. 


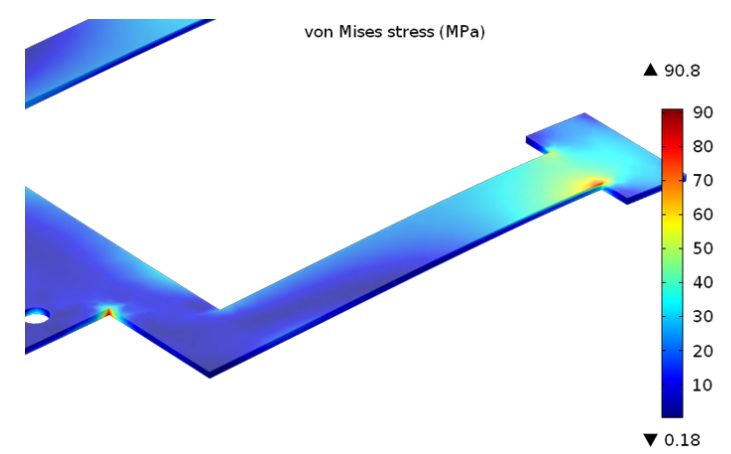

Fig. 8. Close-up view of maximum stress prone areas in the gold membrane.

Fig. 9. Vertical displacement of membrane in a Z direction.

Table 2. Spring constant and actuation voltage.

\begin{tabular}{ccc}
\hline $\begin{array}{c}\text { Membrane's } \\
\text { Material }\end{array}$ & $\begin{array}{c}\text { Spring Constant } \\
{[\mathrm{N} / \mathrm{m}]}\end{array}$ & $\begin{array}{c}\text { Actuation Voltage } \\
{[\mathrm{V}]}\end{array}$ \\
\hline Gold $(\mathrm{Au})$ & 3.02 & 16.0 \\
\hline Aluminium $(\mathrm{Al})$ & 2.65 & 14.1 \\
\hline Titanium $(\mathrm{Ti})$ & 3.83 & 18.5 \\
\hline Platinum $(\mathrm{Pt})$ & 5.68 & 22.6 \\
\hline
\end{tabular}

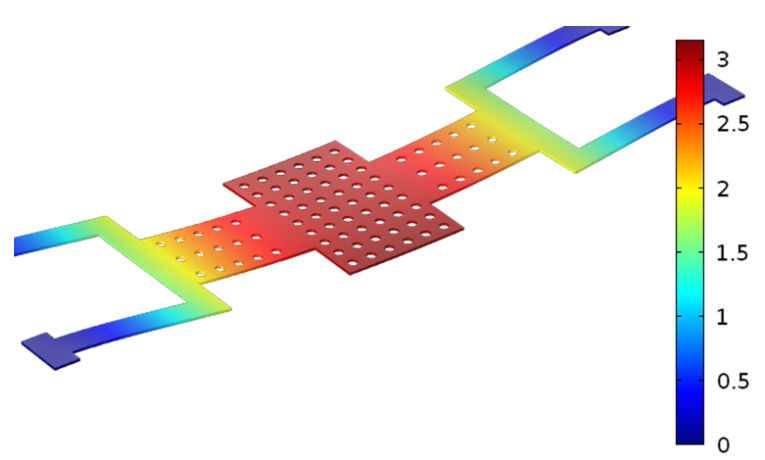

Fig. 10. Maximum displacement of the membrane in a downward direction towards the signal line.

The spring constant and actuation voltage requirement values for different materials are given in Table. 2 . The values given are simulated. The error between the measured and simulated values is minute. Hence, the simulated values are preferred. From the results, we can conclude that the use of titanium in RF MEMS switches increases the robustness and stress handling capability with a trade-off of higher actuation voltage. Titanium limits the design of low-voltage switches. As titanium is a tough material, the processes required for fabrication using this material differ to the processes that are common for fabrication using gold and aluminium.

\section{RF PERFORMANCE ANALYSIS}

The RF performance is simulated using commercially avail-

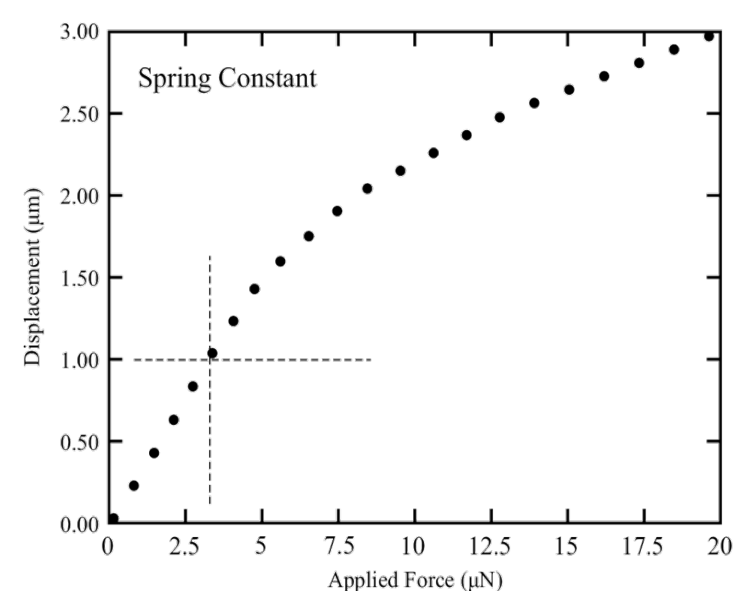

Fig. 11. Effective spring constant estimation of the designed membrane.

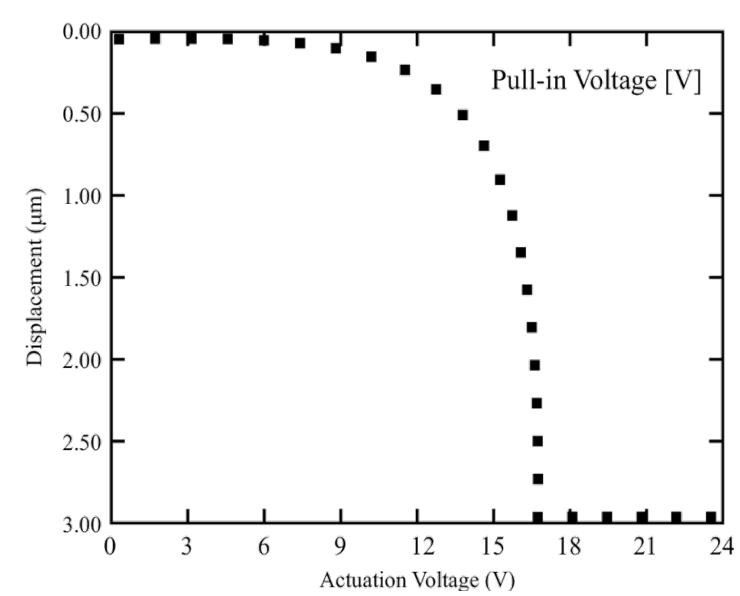

Fig. 12. Simulation of pull-in voltage requirement of the RF MEMS switch membrane.

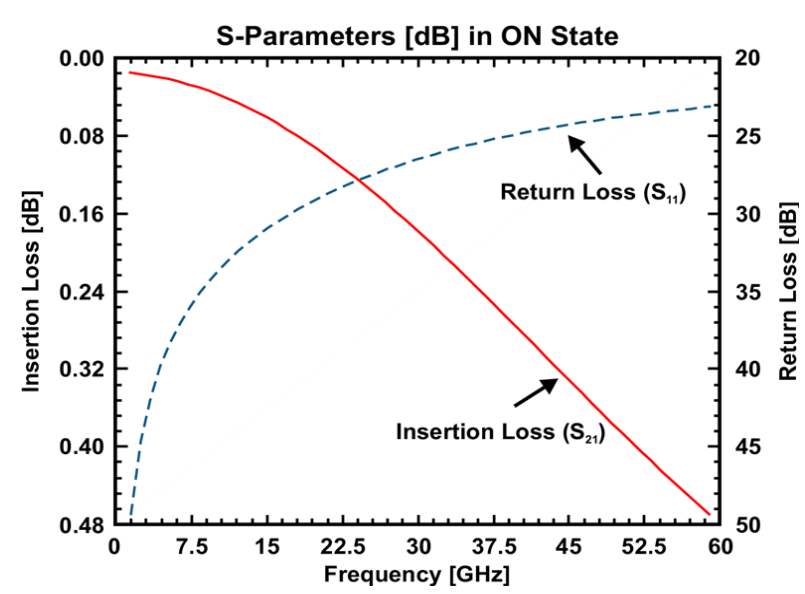

Fig. 13. Simulated S-parameters in the ON state of the MEMS switch from 1 to $60 \mathrm{GHz}$ frequency range and optimised for Q-band.

able electromagnetic field (EM) solver, Ansys HFSS. The scattering parameters are computed for a frequency sweep of 160 for both the ON and OFF state of the switch. The proposed switch shows excellent isolation above 38 in the Q-band and a maximum peak of 2 at 42 . Low insertion loss is observed as 0.32 in 


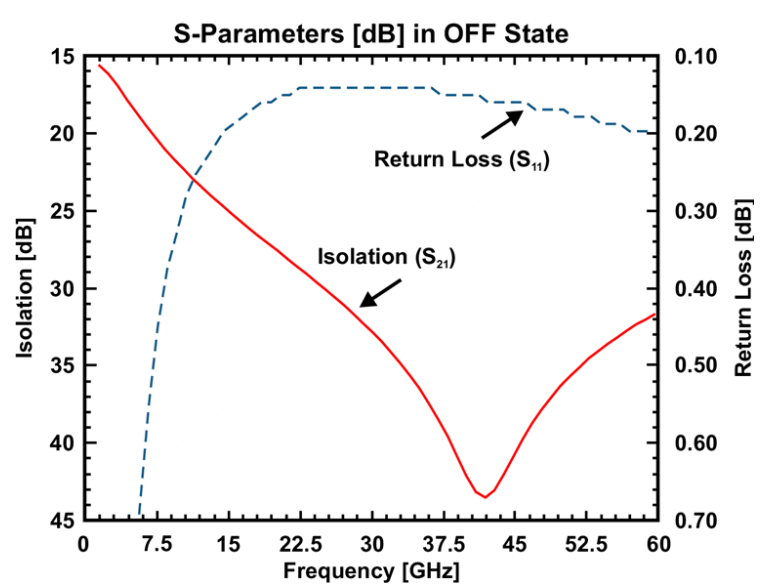

Fig. 14. Simulated S-parameters in the OFF state of the RF MEMS switch from 1 to $60 \mathrm{GHz}$ frequency range and optimised for Q-band.

Table 3. RF performance analysis.

\begin{tabular}{ccccc}
\hline $\begin{array}{c}\text { Frequency } \\
\text { Range }(\mathrm{GHz})\end{array}$ & $\begin{array}{c}\text { Isolation }\left(\mathrm{S}_{21}\right) \\
\text { in OFF State }\end{array}$ & $\begin{array}{c}\text { Insertion } \\
\text { Loss }\left(\mathrm{S}_{21}\right) \text { in } \\
\text { ON State }\end{array}$ & $\begin{array}{c}\text { Return Loss } \\
\left(\mathrm{S}_{11}\right) \text { in OFF } \\
\text { State }\end{array}$ & $\begin{array}{c}\text { Return Loss } \\
\left(\mathrm{S}_{11}\right) \text { in ON } \\
\text { State }\end{array}$ \\
\hline \hline 42 & $=44$ & $=0.32$ & $=0.15$ & $=26$ \\
\hline Q-band & $>38$ & $<0.24$ & $<0.13$ & $>25$ \\
\hline $1-20$ & $>25$ & $<0.08$ & $<0.25$ & $>38$ \\
\hline $20-60$ & $>40$ & $<0.43$ & $<0.16$ & $>28$ \\
\hline
\end{tabular}

the Q-band and 0.05 in the $\mathrm{X}$-band. S-parameters viz. isolation in the OFF state, insertion loss in the ON state and return loss in both the ON and OFF states are shown in Fig. 13 and in Fig. 14, respectively.

Despite the fact that the proposed shunt RF MEMS switch results in excellent RF performance, the switch is usually optimized to maximize the switch performance until the Q-band. This switch can also be used for a higher frequency range (:>55:) with moderate RF performance. The S-parameters for both states are given in Table. 3 .

\section{CONCLUSIONS}

RF MEMS switches provide tremendous advantages over their semiconductor counterparts. With advancements in surface micro-machining, the proposed switch is designed/modelled using a finite element modeller and its performance evaluation and various parameters are analysed and compared with different materials. The switch is designed to overcome the most common problem of RF MEMS switches - high electrostatic actuation voltage requirements. The designed membrane has holes to overcome air the damping problem and meanders to address the high voltage requirements. Excellent RF performance, low voltage requirements, and robustness in the forefront have been analysed for this switch. The switch is optimised for Q-band operation. The proposed RF MEMS switch can potentially be used for many applications in space stations, communication networks and in systems that require low voltage.

\section{REFERENCES}

[1] C. L. Goldsmith, T. Lin, B. Powers, W. Wu, and B. Norvell, IEEE International MTT-S Symposium Digest, 1, 91 (1995).

[2] Z. J. Yao, S. Chen, S. Eshelman, D. Denniston, and C. L. Goldsmith, IEEE Journal of Microelectromechanical Systems, 8, 129 (1999).

[3] T. Singh, Trans. Electr. Electron. Mater., 14, 172 (2013).

[4] C. Ding, X. Huang, G. Gregori, E. R. Parker, M. P. Rao, D. R. Clarke, and N. C. MacDon- ald, Proc. of the 2005 ASME International Mechanical Engineering Congress and Exposition (Orlando, 2005) p. 1-4.

[5] T. Singh, Journal of Computational Electronics, 14, 167 (2015).

[6] M. F. Aimi, M. P. Rao, N. C. MacDonald, A. S. Zuruhi, and D. P. Bothman, Nature Materials (Letters), 3, 103 (2004).

[7] T. Singh and F. Pashaie, Microsystem Technologies, 1 (2014). [DOI: http://dx.doi.org/DOI: 10.1007/s00542-014-2329-y 2014]

[8] T. Singh and K. J. Rangra, Microsystem Technologies, 1 (2015). [DOI: http://dx.doi.org/10.1007/s00542-015-2411-0 2015]

[9] T. Singh and N. Khaira, The Scientific World Journal, 2014, 1 (2014).

[10] T. Singh, Electronics, 17, 105 (2013).

[11] G. M. Rebeiz, RF MEMS: Theory, Design, and Technology. New York: Wiley-Interscience, 2003.

[12] C. O'Mahony, M. Hill, P. J. Hugher, and W. A. Lane, Journal of Micromechanics and Microengineering, 12, 438 (2002).

[13] D. Peroulis, S. Pacheco, K. Sarabandi, and L. P. Katehi, IEEE Transactions on Microwave Theory and Techniques, 51, 259 (2003).

[14] M. Lishchunska, N. Cordero, O. Slattery, and C. O'Mahony, Sensor Letters, 4, 200 (2006).

[15] T. Singh and F. Pashaie, Journal of Computing Science and Engineering, 8 (2014). 